\title{
A Fatal Cause for a Common Presentation
}

\author{
${ }^{1}$ Henry Emanuel, ${ }^{2}$ Robert Willis
}

\begin{abstract}
Upper airway obstruction in the pediatric population has a myriad of etiologies, some of which are easily overseen. We emphasize the importance of thorough airway examination and careful attention to unusual signs, which, in this case, uncovered a fatal tumor.
\end{abstract}

Keywords: Burkitt's lymphoma, Head and neck cancer, Pediatric sleep disordered breathing.

How to cite this article: Emanuel $\mathrm{H}$, Willis R. A Fatal Cause for a Common Presentation. Int J Head Neck Surg 2015;6(4):178-180.

\section{Source of support: Nil}

\section{Conflict of interest: None}

\section{BACKGROUND}

Adenotonsillar hypertrophy $(\mathrm{AH})$ and its sequelae in the pediatric population have been considered for well over 100 years. In 1889, it was suggested that obstruction of the upper airway in such affected children caused "backwardness and stupidity."1 We now have a greater understanding of the neurobehavioral abnormalities seen in obstructive sleep apnea (OSA) that Hill was referring to. Moreover, the many other sequelae of OSA seen in adults (namely, cardiovascular, and metabolic effects) have also been demonstrated in children. ${ }^{2}$

The collection of sleep-related airway problems encountered in childhood (snoring, sleep disordered breathing (SDB) and OSA) do not always present with obvious structural airway obstruction ${ }^{2}$ and nor is a seemingly obvious airway obstruction in these patients always the root cause of the problem. The pathogenesis of these disorders is more complex and multifactorial. Only $71 \%$ of 110 children with OSA and $\mathrm{AH}$ who underwent adenotonsillectomy had successful remission of OSA. ${ }^{3}$ Obesity, craniofacial abnormalities, neuromuscular disorders, exposure to smoking, and prematurity contribute to the pathogenesis of SDB. ${ }^{2}$

\footnotetext{
${ }^{1}$ Registrar, ${ }^{2}$ Consultant

1,2Department of Otolaryngology Head and Neck Surgery Waikato District Health Board, Hamilton, Waikato, New Zealand

Corresponding Author: Henry Emanuel, Registrar Department of Otolaryngology Head and Neck Surgery Waikato District Health Board, Hamilton, Waikato, New Zealand Phone: 0212227620, e-mail: henary@gmail.com
}

Due to many uncontrollable factors, only $10 \%$ of children thought to have such a disorder receive the gold standard diagnostic testing with polysomnography. ${ }^{2}$ Unfortunately, surrogate diagnostic tests including questionnaires, home pulse oximetry, and home PSG have questionable validity for diagnosing SBD or OSA. ${ }^{4}$ We are therefore often left to depend upon careful history and clinical examination to diagnose these conditions. Despite the knowledge that these alone cannot reliably confirm these diagnoses, we emphasize the importance of these fundamentals with a case where a highly virulent tumor presents with some typical features of benign upper airway obstruction.

\section{CASE REPORT}

A 10-year-old girl presented to our Emergency Department with 2 months of sore throat; worsening nasal obstruction; and a parental report of apnea, daytime hypersomnolence, and inattention. She had visited her family physician on a number of occasions and her sore throat was managed with multiple courses of oral antibiotics, to little avail. Her parents had also noted her left eye had become proptosed in the preceding week, causing increasing concern and leading to the current presentation. Intermittent left visual blurring was also reported, with no orbital pain.

On examination, she had hyponasal speech, was very lethargic, and stertorous. Both nasal cavities were completely obstructed and the chest was clear. The neck was soft with no obvious lymphadenopathy. Examination of the oral cavity was unremarkable with no trismus and grade 2 tonsillar hypertrophy. No erythema or postnasal secretion was evident. Orbital assessment showed no chemosis, normal visual fields, and normal optic nerve function. Proptosis of the left eye was noted clinically and confirmed with exopthalmometer.

On further inspection of her nasal cavity with a pediatric flexible nasendoscope, a large friable soft tissue mass obliterated both nasal cavities at the level of the midseptum. Visualization beyond this into the nasopharynx was not possible.

The child was admitted for investigations and airway observation on the pediatric surgical ward. Parenteral dexamethasone was commenced and co-prescribed with a proton pump inhibitor. Serology showed hemoglobin slight raised at $15.6(\mathrm{H})$, WCC $11.7(\mathrm{H})$, Neutorphils $9.2(\mathrm{H})$, and 

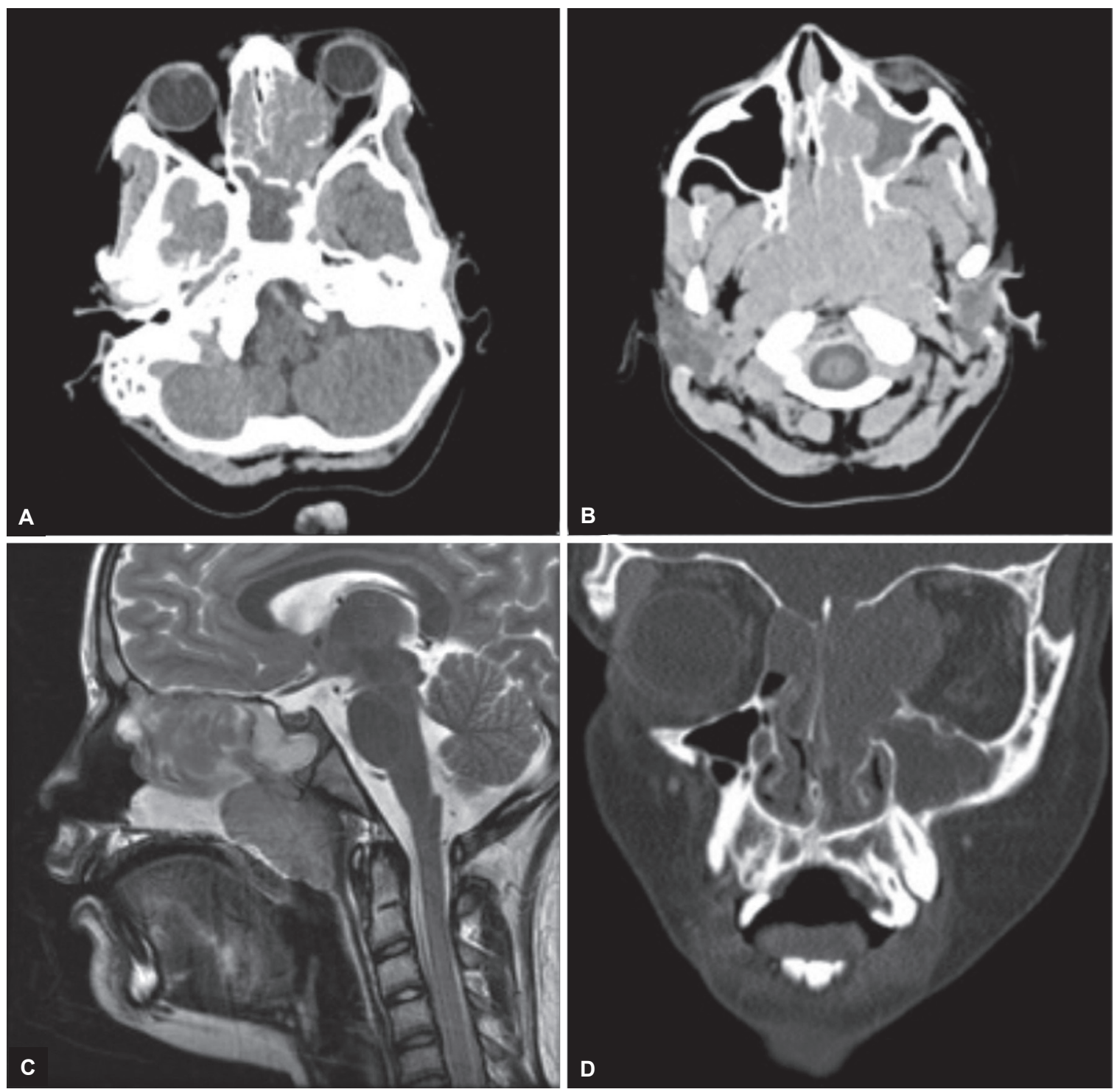

Figs 1A to D: Computer tomography and MRI illustrating expansile and destructive lesion of the ethmoid bone $(A)$, obliterating the nasopharynx $(B)$, and ex tending into the orbit and anterior cranial fossa $(C$, and $D)$

a normal blood film. Overnight pulse oximetry (Radical-7 oximeter, Masimo. CA, USA) showed over 200 desaturations with a nadir of $85 \%$. No bradycardia was recorded.

Urgent computed tomography (CT) and magnetic resonance imaging (MRI) scans (Figs 1A to D) of the head and neck were performed. A large tumor originating from the ethmoid air cells and obliterating the nasopharynx was seen. Bony erosion was seen with a tumor extending through the cranial base into the anterior cranial fossa. Invasion was also seen into the left orbit via the lamina papyracea.

Transnasal biopsies of the tumor were obtained, showing Burkitt's lymphoma (BL). Urgent referral was expedited for pediatric hem-oncology input at our regional tertiary pediatric hospital. The patient underwent five cycles of chemotherapy, including intrathecal treatment for positive cerebrospinal fluid cytology. Unfortunately, she developed early recurrence in the deep cervical lymph nodes and succumbed to the disease 5 months after presentation.

\section{DISCUSSION}

Sleep disordered breathing and OSA are common childhood presentations to ENT clinics. Causes of this include $\mathrm{AH}$, developmental disorder, inflammatory or infective processes, trauma, and much less commonly, neoplasms. Here we present a case of sporadic BL arising unusually from ethmoid air cells. Orbital involvement is rare in non endemic/sporadic BL but has been previously reported. ${ }^{5,6}$ The tumor has an extremely rapid growth with a doubling rate of just 24 to 48 hours, and urgent diagnosis and treatment are essential.

Denis Burkitt, when in Uganda in 1958, observed a high rate of jaw and abdominal tumors origination from lymphoid tissue in children. ${ }^{7}$ Later, Epstein, Barr, and 
Achong found viral particles within the tissue of these tumors. Indeed, this endemic form of the disease was first described and usually presented with swelling of the jaws, periorbital swelling, or retroperitoneal mass. It is almost always associated with Epstein-Barr virus (EBV) infection in areas where malaria is endemic. ${ }^{8}$ In such areas (Papua New Guinea, sub-Saharan Africa), it accounts for half of all childhood cancers (incidence is $40-50$ per million people under 18 years) but is rare elsewhere. ${ }^{9}$ In contrast, a sporadic form is found in areas not affected by malaria and is very rarely associated with EBV infection. Typically, these patients present with abdominal tumors, but the head and neck lymphoid tissue can also be involved. The incidence of sporadic BL is comparatively rare with an incidence of 2 per 1 million people under 18 years. ${ }^{10}$

A third variant, $\mathrm{HIV}$-associated BL, appears to occur independent of immune suppression and is seen in HIV-infected patients with high CD4 counts. Human immunodeficiency virus chronically stimulates B cell populations and is thought to possibly underpin development of lymphoma in these patients. ${ }^{10}$

Histologically, the above forms of BL are identical. The common histologic finding is a diffuse proliferation of monomorphic B cells with abundant basophilic cytoplasm. The classical "starry sky" appearance is created by numerous tingible macrophages (containing condensed ingested nuclear material) surrounded by a clear space. ${ }^{11}$ At the genetic level, translocation of the transcription factor gene c-MCY is universal and accounts for the development of cancer. The precise role of EBV and other cofactors in oncogenesis is incompletely understood.

Treatment of BL is with multiagent chemotherapy protocols, and surgery only plays a role for biopsy. Cure rates in limited-stage disease is approximately 85 to $95 \%$ at 5 years, and for advanced stage has increased to 75 to $85 \%$, being hailed as one of the success stories of modern pediatric oncology. ${ }^{9}$ Relapse is uncommon 1 year out from treatment, but harbors a much poorer prognosis as it did in this case.

\section{CONCLUSION}

Endoscopic evaluation remains the gold standard for assessment of the pediatric upper airway, with imaging as an adjunct in selected cases. ${ }^{12}$ We believe this approach facilitated a timely biopsy and diagnosis, which is pertinent in such a rapidly progressive disease. The importance of recognizing unusual clinical signs is also illustrated here. Proptosis is an uncommon presenting sign and in one-third of pediatric patients is caused by a neoplasm. ${ }^{13}$ A high index of suspicion and a methodical approach to pediatric upper airway obstruction will effectively diagnose rare causes for the very common presenting symptom of pediatric SDB.

\section{ACKNOWLEDGMENTS}

We wish to thank The Waikato Hospital Paediatric department for their timely involvement and ongoing support for surgical specialties when caring for severely unwell children. Also, we thank the Auckland and Starship Hospital Oncology and ORL departments for their assistance and intervention.

\section{REFERENCES}

1. Hill W. On some causes of backwardness and stupidity in children: and the relief of these symptoms in some instances by nasopharyngeal scarifications. Br Med J 1889 Sep;2(1500):711-712.

2. Witmans M, Young R. Update on pediatric sleep-disordered breathing. Pediatr Clin North Am 2011 Jun;58(3):571-589.

3. Tauman R, Gulliver TE, Krishna J, Montgomery-Downs HE, O’Brien LM, Ivanenko A, Gozal D. Persistence of obstructive sleep apnea syndrome in children after adenotonsillectomy. J Pediatr 2006 Dec;149(6):803-808.

4. Lumeng JC, Chervin RD. Epidemiology of pediatric obstructive sleep apnea. Proc Am Thorac Soc 2008 Feb15;5(2):242-252.

5. Blakemore WS, Ehrenberg M, Fritz KJ, Variajokis D. Rapidly progressive proptosis secondary to Burkitt's lymphoma. Origin in the ethmoidal sinuses. Arch Ophthalmol 1983 Nov;101(11):1741-1744.

6. Gupta R, Yadav JS, Yadav S, Wadood A. Orbital involvement in nonendemic Burkitts lymphoma. Orbit 2012 Dec;31(6):441-445.

7. Burkitt D. A sarcoma involving the jaws in African children. Br J Surg 1958 Nov;46(197):218-223.

8. Fujita S, Buziba N, Kumatori A, Senba M, Yamaguchi A, Toriyama K. Early stage of Epstein-Barr virus lytic infection leading to the "starry sky" pattern formation in endemic Burkitt lymphoma. Arch Pathol Lab Med 2004 May;128(5): 549-552.

9. Sandlund JT, Downing JR, Crist WM. Non-Hodgkin's lymphoma in childhood. N Engl J Med 1996 May 9;334(19): 1238-1248.

10. Molyneux EM, Rochford R, Griffin B, Newton R, Jackson G, Menon G, Harrison CJ, Israels T, Bailey S. Burkitt's lymphoma. Lancet 2012 Mar 31;379(9822):1234-1244.

11. Kumar V, Abbas AK, Aster JC, Robbins SL. Robbins basic pathology. 9th ed. Philadelphia (PA): Elsevier/Saunders; 2013. xii, $910 \mathrm{p}$.

12. Gysin C. Evaluation of the pediatric airway. Rev Med Suisse 2008 Oct 1;4(173):2089-2090, 2092-2093.

13. Masud MZ, Babar TF, Iqbal A, Khan MT, Zaffar ul I, Khan MD. Proptosis: etiology and demographic patterns. J Coll Physicians Surg Pak 2006 Jan;16(1):38-41. 